\title{
Chronic Eosinophilic Pneumonia in a Breast Cancer Patient Post-Radiation Therapy: A Case Report
}

\author{
Said Chaaban MD and Victor Salloum MD
}

\section{Introduction}

Chronic eosinophilic pneumonia (CEP) is a syndrome associated with nonspecific pulmonary and atopic manifestations, chest imaging findings suggestive of peripheral alveolar opacities, and alveolar and blood eosinophilia. ${ }^{1}$ Onset is insidious, with symptoms lasting up to 2-4 weeks. It is usually idiopathic; however, it has been associated with drugs, allergy shots, parasites, irradiation for breast cancer, and rheumatoid arthritis. ${ }^{2,3}$ It is a rare disease and usually a diagnosis of exclusion. ${ }^{4}$ CEP was first described by Carrington in $1969 . .^{5}$ In this case, a female patient with a history of allergic rhinitis and breast cancer developed CEP 6 years after she completed radiation therapy.

\section{Case Report}

A 51-year-old female with a medical history significant for left-sided breast cancer underwent two lumpectomies in 2005, for which the pathology was ductal carcinoma in situ. She was placed on tamoxifen, and only radiation treatment was pursued. She presented after 7 years with a 3-month history of shortness of breath that was mainly on exertion. She noticed a significant decline in her exercise performance secondary to her dyspnea. Her symptoms were associated with a dry cough, occasional wheezing, and heaviness in her chest. She also complained of sinus pressure and congestion. She had never smoked and was not

Both authors are affiliated with the Department of Internal Medicine, University of Kansas School of Medicine-Wichita, Wichita, Kansas.

The authors have declared no conflicts of interest.

Dr Chaaban presented a poster related to this paper at the American College of Chest Physicians Annual Meeting, held October 20-25, 2012, in Atlanta, Georgia.

Correspondence: Said Chaaban MD, Department of Internal Medicine, University of Kansas School of Medicine-Wichita, 1010 North Kansas, Wichita, KS 67214. E-mail: schaaban@kumc.edu.

DOI: $10.4187 /$ respcare. 02458 known to have any respiratory or rheumatologic disease. Her medications were restricted only to vitamins.

She had allergies to penicillin and to adhesive tape. On review of systems, the patient reported suffering from nocturnal sweats but no fevers, no change in appetite, and no weight loss.

She was first prescribed fluticasone propionate/salmeterol and albuterol/ipratropium inhalers, with no improvement in her symptoms. The patient was also given antibiotics and steroids. She responded well to prednisone.

Her chest X-ray was clear (Fig. 1), and the computed tomography (CT) scan of the chest (Fig. 2) revealed a left lower and a medial right lower lobe ground-glass appearance with mildly enlarged hilar and paratracheal lymphadenopathy.

She was referred to the pulmonology clinic thereafter for further evaluation. Pulmonary function tests revealed a normal $\mathrm{FEV}_{1} / \mathrm{FVC}$ ratio, total lung capacity, and diffusing capacity of the lung for carbon monoxide. A two-dimensional transthoracic echocardiogram revealed a normal ejection fraction and no evidence of pulmonary hypertension. She then underwent a bronchoscopy with a transbronchial biopsy. Bronchoalveolar lavage fluid (BALF) had significant eosinophilia (37\%).

Histopathology showed focal organizing pneumonia and mild chronic inflammatory infiltrates with rare eosinophils (Fig. 3). Bronchial bacterial and fungal cultures were negative.

The patient was treated with oral prednisone at $1 \mathrm{mg} / \mathrm{kg}$ with significant improvement in symptoms. Her CT scan of the chest was repeated after 1 month with no change. Her prednisone was tapered slowly over 1 month and consequently stopped. The patient's symptoms recurred but were much less severe, and she is currently on montelukast to control her underlying allergic rhinitis with the aim of controlling her CEP. ${ }^{1}$

\section{Discussion}

CEP is a rare disease. ${ }^{4}$ Its prevalence remains unknown; however, it constitutes $\sim 0-2.5 \%$ of the cases of interstitial lung diseases. ${ }^{5} \mathrm{CEP}$ is a disease of both females and males, 


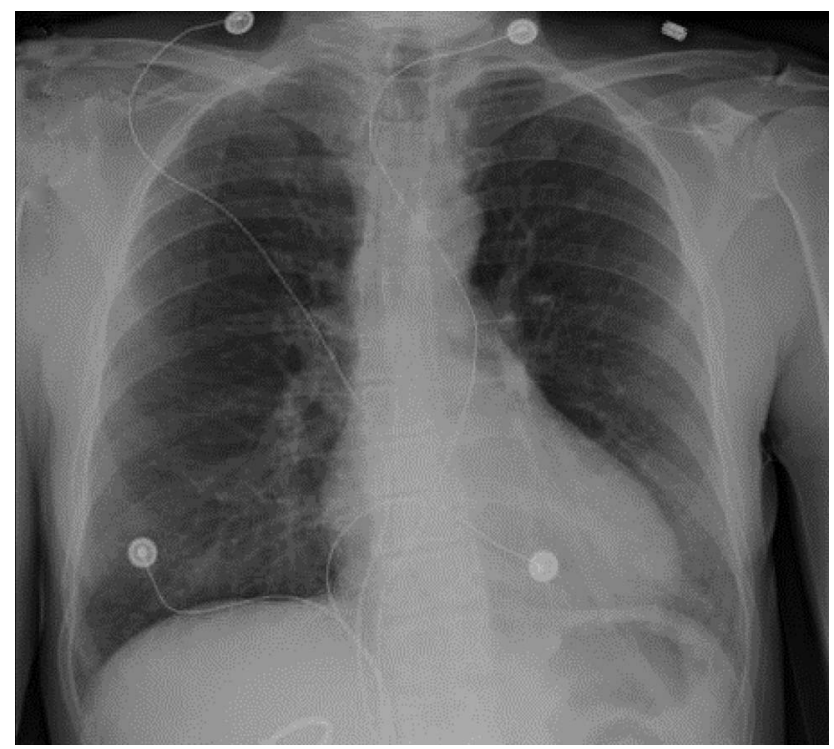

Fig. 1. Chest x-ray. No acute cardiopulmonary process.

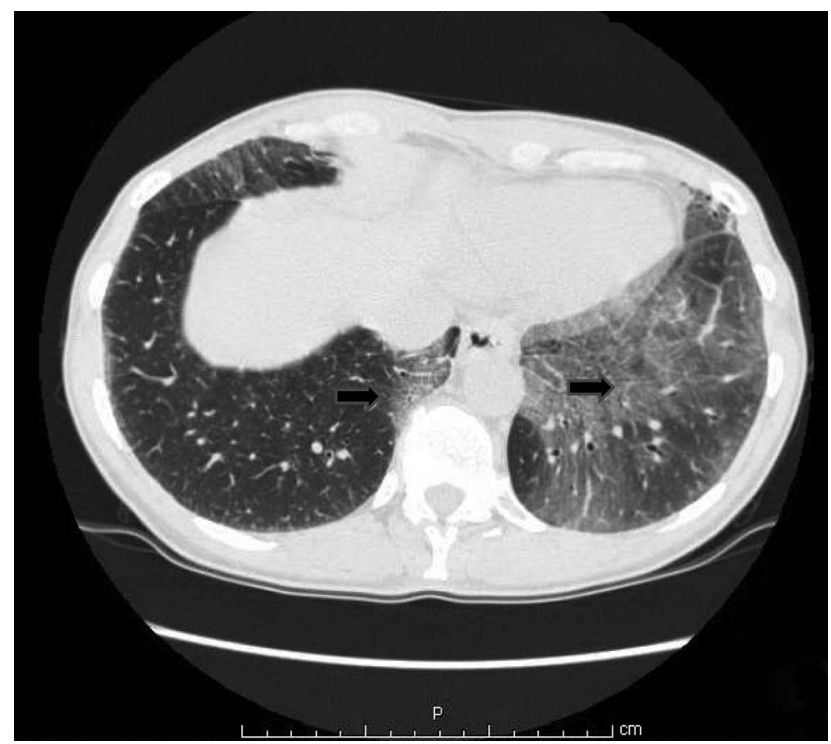

Fig. 2. High-resolution computed tomography (CT) of the chest showing areas of interstitial lung disease and ground glass opacity (arrows).

with a preponderance in females. ${ }^{4-7}$ It is extremely rare in children and has a peak incidence in adults of 50 years of age. ${ }^{4,5} \mathrm{~A}$ third to a half of affected patients have a history of asthma, and $\sim 90 \%$ of the cases either are nonsmokers or have a remote history of smoking, thus signifying a possible protective role for smoking. $4,5,7$

It is usually a diagnosis of exclusion, thus the need to exclude other causes of peripheral and lung eosinophilia. ${ }^{4}$ Extrapulmonary manifestations are rare, and if present, the differential would include Churg-Strauss or hypereosinophilic syndrome. ${ }^{5}$

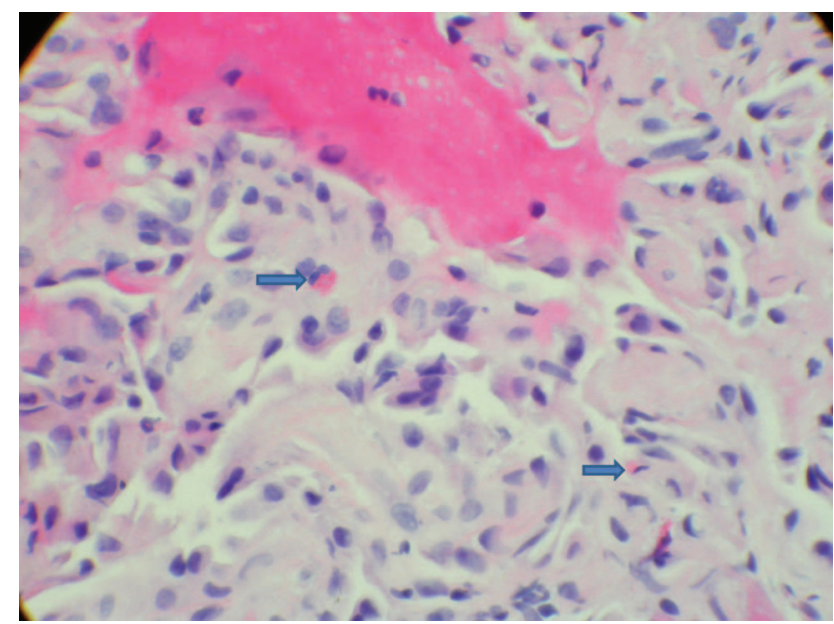

Fig. 3. Biopsy. High-power view 400×; hematoxylin and eosin stain, eosinophils noted (arrows).

Diagnosis is made based on clinical criteria, radiological findings, and eosinophilia present in either the blood or BAL. ${ }^{3,4}$ Response to steroids aids in confirming the diagnosis and is usually within $24-48$ hours, with dramatic improvement in symptoms. ${ }^{3}$

On review of systems, patients may present with asthenia, nocturnal sweats, fever, and weight loss, occurring over $>2$ months. ${ }^{5,6}$ Blood may reveal peripheral eosinophilia and elevated levels of $\mathrm{IgE}$ in $90 \%$ and $50 \%$ of the cases, respectively. ${ }^{4}$ Erythrocyte sedimentation rate and C-reactive protein may also be elevated. ${ }^{4}$

Eosinophilia identification is important for diagnosis and can be determined by BAL $\geq 25 \%$. $^{1,4,5,8}$ This proves the eosinophilic nature of the lung injury. Increased eosinophilia in BAL is secondary to a suppressed Fas-mediated apoptosis, thus prolonging the survival of those apoptotic cells. ${ }^{4}$

A biopsy is not required to establish a diagnosis but may demonstrate eosinophilic infiltration of the interstitium and alveolar lumen, organizing pneumonia, or inflammatory cells. ${ }^{4,9}$

Pulmonary function tests usually reveal a restrictive defect but can be normal. ${ }^{4,9}$ Hypoxemia is noted in arterial blood gases. ${ }^{4}$ Chest imaging may show a consolidation or a ground-glass appearance. ${ }^{4,8}$ Chest $\mathrm{x}$-ray may be normal in $80 \%$ of patients. ${ }^{10}$

As part of the treatment for breast cancer, radiation therapy has been shown to lead to CEP, especially in those who have underlying allergies such as asthma or atopic manifestations..$^{1,11}$ Usually the areas that are irradiated are the ones that may develop CEP. ${ }^{1}$ High-resolution CT is highly sensitive in the detection of lung injury post-radiation. ${ }^{10}$ Radiation therapy may predispose for CEP; however, a trigger such as an environmental exposure, drugs, and Aspergillus is usually needed. ${ }^{1}$ The proposed mechanism is priming followed by an antigenic stimulation. ${ }^{1,12}$ 
The patient presented is a runner, thus putting her at high risk of exposure to environmental allergens.

A multi-center study performed by Group d'Etudes et de Recherche sur les Maladies "Orphelines" Pulmonaires identified 5 patients with CEP post-radiation therapy for breast cancer, all of which presented within 12 months. ${ }^{13}$ They had a median presentation of symptoms 3.5 months after completion of radiation therapy.,14 Our patient met all criteria for the diagnosis of CEP; however, she presented 6 years after completion of her radiation therapy.

Spontaneous resolution occurs only in $10 \%$ of patients. ${ }^{15}$ Management usually includes systemic steroids, with response to therapy within 1-2 weeks; however, the likelihood of relapse is high after tapering steroids. ${ }^{16-18}$ When followed up to 10 years, $83 \%$ of patients relapsed. ${ }^{15}$

This dramatic response to steroids has raised the question of the use of steroids as a diagnostic challenge..$^{5,6}$ The treatment dose is $0.5-1 \mathrm{mg}$ of prednisone $/ \mathrm{kg} / \mathrm{d} .{ }^{5}$

The use of inhaled corticosteroids alone in the management of CEP is not optimal; however, when combined with systemic steroids, inhaled corticosteroids may improve the ability to taper and decrease the duration of treatment. ${ }^{16,19}$ At least 6 months of tapering the dose of steroids is recommended. ${ }^{6}$ If a patient has a recurrence after the taper is over, treatment should be for up to 1 year before discontinuing steroids. ${ }^{6}$ If severe, vincristine and hydroxyurea have been shown to improve prognosis. Plasmapheresis has been used, but its benefit is unknown. ${ }^{8}$

A delay in initiation of the treatment may lead to fibrosis because an eosinophil is a toxic cell. ${ }^{4}$ After treatment, residual pathological defects, including peribronchial fibrosis and a healed granuloma, have been described. ${ }^{20}$

Our patient met the diagnosis of CEP, and the relapse of her disease after discontinuation of steroids aided in confirming this diagnosis. Clinicians in general and pulmonologists in particular should consider CEP as a diagnosis in patients who have had previous exposure to radiation therapy irrespective of the time of exposure.

\section{Teaching Points}

- The diagnosis of CEP is made based on the clinical picture, radiological findings, and blood or BAL eosinophilia.

- Radiation therapy of the chest as part of the treatment for breast cancer has been shown to lead to CEP, especially in those with underlying allergies.

- Management includes systemic use of steroids, with a slow taper over at least 6 months.

- CEP should be considered in patients with previous exposure to radiation therapy irrespective of time of exposure.

\section{REFERENCES}

1. Cottin V, Frognier R, Monnot H, Levy A, DeVuyst P, Cordier JF. Chronic eosinophilic pneumonia after radiation therapy for breast cancer. Eur Respir J 2004;23(1):9-13.

2. Jaimes-Hernández J, Mendoza-Fuentes A, Meléndez-Mercado CI, Aranda-Pereira P. Chronic eosinophilic pneumonia: autoimmune phenomenon or immunoallergic disease? Case report and literature review. Reumatol Clin 2012;8(3):145-148.

3. Campos LE, Pereira LF. Pulmonary eosinophilia. J Bras Pneumol 2009;35(6):561-73.

4. Tzilas V, Bastas A, Koti A, Papandrinopoulou D, Tsoukalas G. A 77 year old male with peripheral eosinophilia, pulmonary infiltrates and a small pleural effusion. Eur Rev Med Pharmacol Sci 2009;13(3): 227-232.

5. Marchand E, Cordier JF. Idiopathic chronic eosinophilic pneumonia. Orphanet J Rare Dis 2006;1:11.

6. Umeki S, Soejima R. Acute and chronic eosinophilic pneumonia: clinical evaluation and the criteria. Intern Med 1992;31(7):847-856.

7. Jeong YJ, Kim KI, Seo IJ, Lee CH, Lee KN, Kim KN, et al. Eosinophilic lung diseases: a clinical, radiologic, and pathologic overview. Radiographics 2007;27(3):617-637

8. Thiruchelvam JK, Penfold CN, Akhtar S. Chronic eosinophilic pneumonia associated with T-cell lymphoma. Int J Oral Maxillofac Surg 2002;31(1):112-114.

9. Kagohashi K, Ohara G, Kurishima K, Kawaguchi M, Nakayama H, Ishikawa H, Satoh H. Chronic eosinophilic pneumonia with subpleural curvilinear shadow. Acta Medica (Hradec Kralove);54(1):4548.

10. Järvenpää R, Holli K, Pitkänen M, Hyödynmaa S, Rajala J, Lahtela SL, Ojala A. Radiological pulmonary findings after breast cancer irradiation: A prospective study. Acta Oncol 2006;45(1):16-22.

11. Guerriero G, Battista C, Montesano M, Carino R, Primavera A, Costantino $\mathrm{S}$, et al. Unusual complication after radiotherapy for breast cancer bronchiolitis obliterans organizing pneumonia case report and review of the literature. Tumori 2005;91(5):421-423.

12. Cottin V, Cordier JF. Eosinophilic pneumonias. Allergy 2005;60(7): 841-857.

13. Solomon J, Schwarz M. Drug-, toxin-, and radiation therapy-induced eosinophilic pneumonia. Semin Respir Crit Care Med 2006;27(2): 192-197.

14. Camus P, Fanton A, Bonniaud P, Camus C, Foucher P. Interstitial lung disease induced by drugs and radiation. Respiration 2004;71(4): 301-326.

15. Alam M, Burki NK. Chronic eosinophilic pneumonia: a review. South Med J 2007;100(1):49-53.

16. Minakuchi M, Niimi A, Matsumoto H, Amitani R, Mishima M. Chronic eosinophilic pneumonia: treatment with inhaled corticosteroids. Respiration 2003;70(4):362-366.

17. Luks AM, Altemeier WA. Typical symptoms and atypical radiographic findings in a case of chronic eosinophilic pneumonia. Respir Care 2006;51(7):764-767.

18. Hayakawa H, Sato A, Toyoshima M, Imokawa S, Taniguchi M. A clinical study of idiopathic eosinophilic pneumonia. Chest 1994; 105(5):1462-1466.

19. Marchand E, Etienne-Mastroianni B, Chanez P, Lauque D, Leclerc $\mathrm{P}$, Cordier JF. Idiopathic chronic eosinophilic pneumonia and asthma: how do they influence each other? Eur Respir J 2003;22(1):8-13.

20. Perrault JL, Janis M, Wolinsky H. Resolution of chronic eosinophilic pneumonia with corticoid therapy. Demonstration by needle biopsy. Ann Intern Med 1971;74(6):951-954. 